\title{
Comparative Study of Librarians in China and America Based on Least Squares and Minitab Analysis
}

\author{
Liping Gao \\ Library Shijiazhuang University, Shijiazhuang China \\ g_ao_liping@126.com
}

Keywords: least squares; linear weighted sum; minitab analysis; covariance matrix; numerical analysis; linear fitting

\begin{abstract}
It is the library that is an indispensable part in the building of advanced culture, the exchanging center of documentation and information, a knowledge base of teaching and scientific research, and second class for people learning knowledge. Moreover, it gives comprehensive and sustained learning opportunities to the people who love learning. Therefore, librarians play a very important role. As librarians ,they should not only classify books , maintain the normal working order of the libraries, but should have advanced knowledge of management and professional skills, providing professional service for readers who need professional books. Through surveys and statistics, this paper has made statistical analysis on the situation of Sino-American librarians. The first part of this paper mainly describes the differences of Sino-American librarians in the settings of librarians, vocational qualification requirements for librarians, and service capabilities and so on. In the second part, by applying non-linear least-squares principle, weighting linear and optimalizing the survey data, the statistical mathematical models has been developed. In the third part, through professional investigation and analysis software, namely, Minitab ,making statistics processing for data, the best representation has been got in the three aspects, that's to say, the settings of librarians , vocational abilities of librarians, and service capabilities. Thus it provides a theoretical basis for the hiring and training of librarians.
\end{abstract}

\section{Introduction}

With the development of society, it is the speed of new knowledge information as well as science and technology's spread and communication that has been more and more faster, in which, library books are the main carrier of communicating [1]. At the same time, scientific research also begins from collecting and knowing the library books, mastering the predecessors' achievements in scientific research, and grasping the situation of domestic and foreign present research [2,3].With the aid of rich books in the library, and through continuous self-study, the readers can acquire new knowledge and professional skills and improve their comprehensive quality. In addition, much attention should be paid to the importance of librarians. On one hand, they can maintain the normal work of the library and the management of library information [4]. On the other hand, they can guide readers to read related classificatory literature. Therefore, the readers can save a lot of time in collecting data [5]. This paper has analyzed and studied the difference of Sino-American librarians, which has been described from the three aspects, namely, the settings of librarians, vocational abilities of librarians, and service capabilities of librarians. In the second part of this paper, by using the weighting linear, theoretical knowledge and the method of numerical successive iteration, the covariance matrix has been solved.And the diagonal value of covariance matrix can be used as a variance calculation [6,7].Ultimately, the estimate value of direct data can be gotten. Using the foreign professional statistical analysis software Minitab, the third part has optimized the results of investigation and statistics, and obtained the optimal allocation chart data of different librarians with different qualities. 


\section{The comparative overview of Sino-American librarians}

There is a very big difference in China and America librarians, which is mainly reflected in three aspects, the settings of librarians, vocational abilities of librarians, and service capabilities of librarians. Details will be shown in the following pages.

\section{A. Settings of librarians}

Settings of librarians include numbers of subject classification and the numbers of librarians. And numbers of subject classification can be in accordance with the department or major [8]. In this paper, we have investigated subject classification and the number of librarians in the United States and China's 160 university librarians, and have listed the top three universities which have the most numbers.

TABLE I. THE SUBJECTS AND NUMBER OF LIBRARIANS IN AMERICA UNIVERSITIES
\begin{tabular}{|l|l|l|}
\hline Universities in America & Subject classification & Numbers of librarians \\
& & \\
\hline University of Washington & 175 & 175 \\
\hline Yale University & 165 & 164 \\
\hline Stanford University & 153 & 151 \\
\hline$\ldots \ldots$ & $\ldots \ldots$ & $\ldots \ldots$ \\
\hline Average Value & 98 & 97 \\
\hline
\end{tabular}

From Table 1, we can see that the average value of settings in American university subjects is 98, and the number of librarians is 97 . Moreover, numbers of librarians and discipline division are basically the same. However, the value of the top three universities are far higher than the average value.

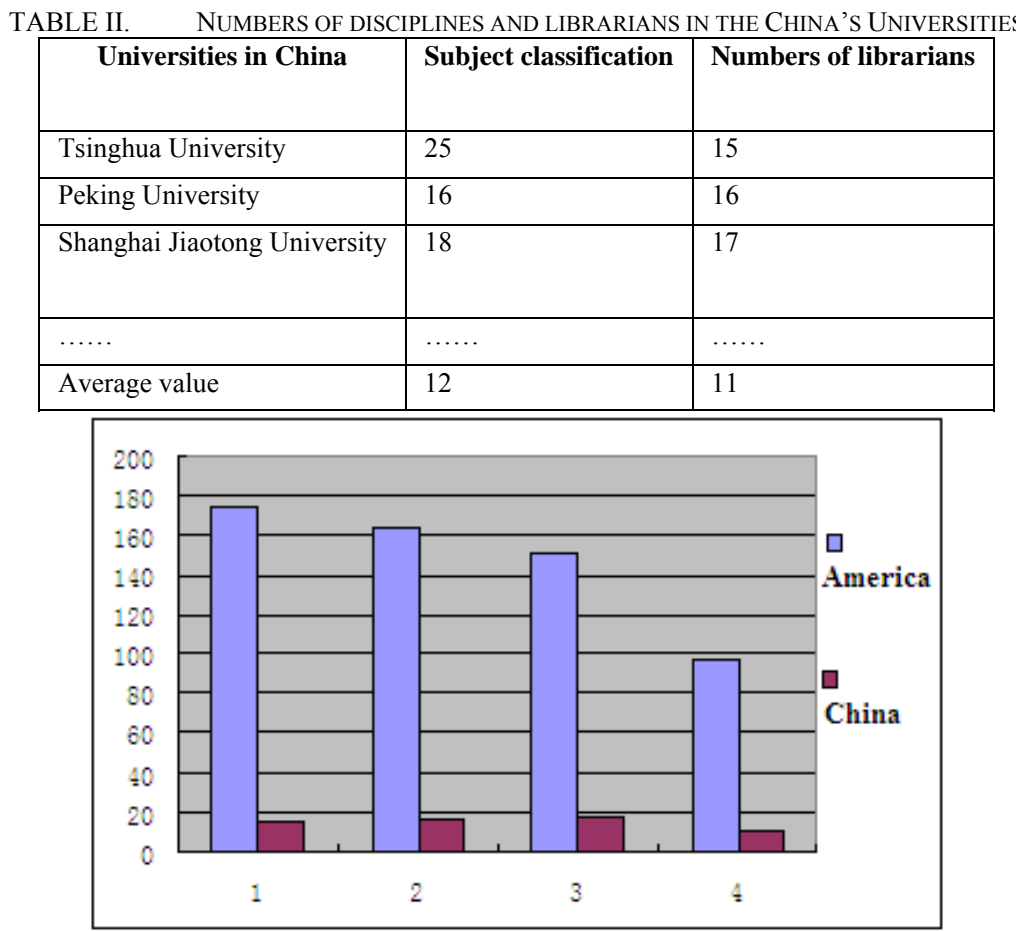

Figure 1.

The comparison of the number of China and America university's professional librarians

From Table 2 and Figure 2 ,we can know that compared with the United States, the division of subject and the number of librarians in China Library is relatively low, and the average value is several times as small as that of the United States. Thus the method of optimization should be sought to optimize the allocation of subject classification and the number of librarians.

B. Professional skills of librarians

Professional skills of librarians reflect the level of information service in the library, and the skill level is mainly reflected in the academic qualifications. In China, there are not too high academic requirements for entering the library to work as a librarian[9]. So this paper made a statistical analysis on the population that the library information science of United States actually recruits and 
analyzed the number of students who are majored in library professionals of China recruit. Then, list the icon which is shown as follows:

TABLE III. COMPARISON OF THE NUMBER OF DISCIPLINE AND PROFESSIONAL SKILLS IN CHINA AND AMERICA UNIVERSITIES

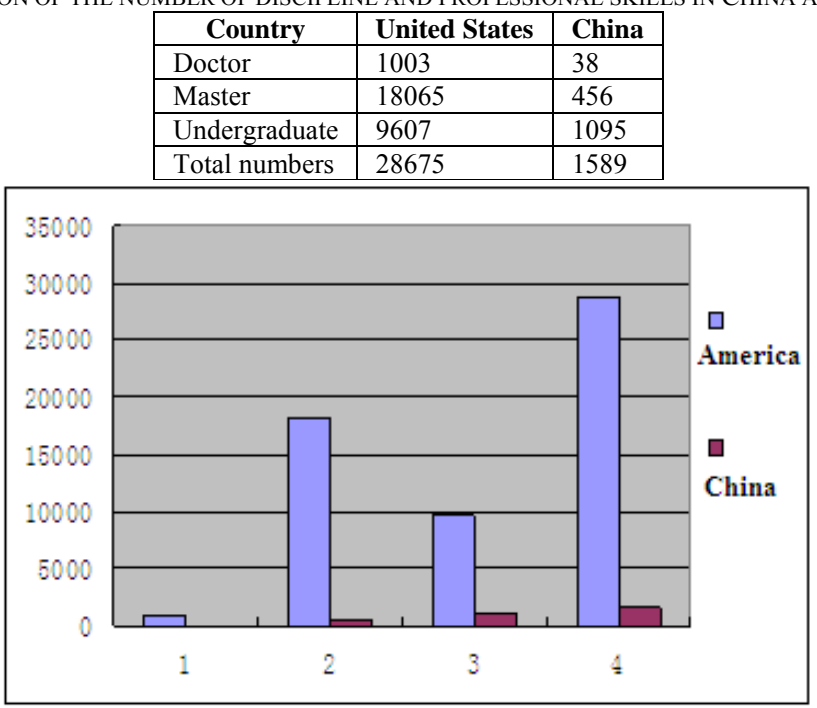

Figure 2.

Comparison of the number of discipline and professional skills in China and America universities

From the comparative Figure of China and America universities' discipline professional skills, we can see that the education level of American University's subject librarian is far higher than that of China, especially the number of masters which is many times higher than that of China. So retraining the qualifications and expertise of librarians are the problems that the Chinese library should further research.

C. Service level

Through investigation and statistics, this paper conducted a survey of the service level of the librarians. There were many ways we had used to investigate the satisfaction degree of people towards librarians[10]. In which, there were mainly three situations, namely, librarian's reply of email, the network connection of the network books and the method of comprehensive evaluation . Finally, statistical results are as follows.

TABLE IV. SERVICE LEVEL'S CONTRAST OF CHINA AND AMERICA UNIVERSITIES' DISCIPLINE

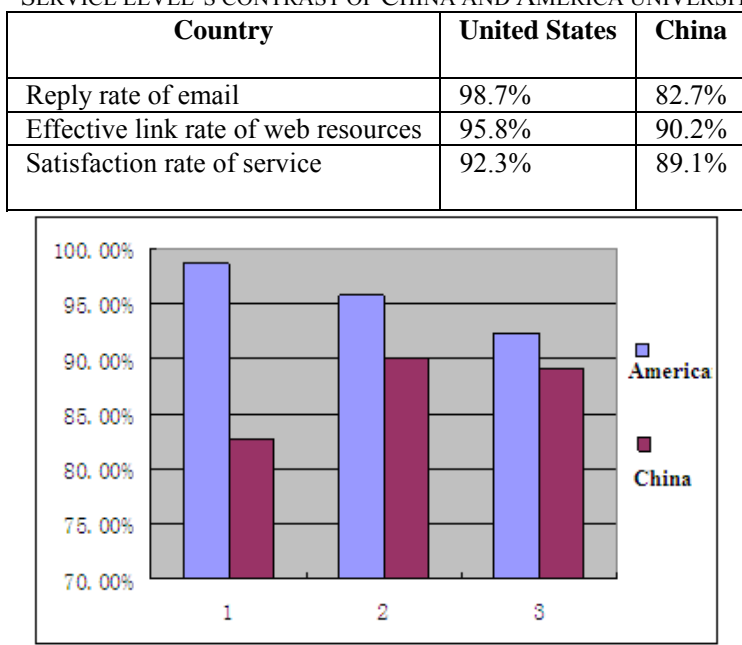

Figure 3.

Service level's contrast of Chinese and American universities' discipline

From the comparative Figure of the service level of China and America universities' librarian, we can see that the service level of American University's librarian is higher than that of China. What's more, effective connection rate of network resources and reply rate of e-mail of American University's librarian are also very high, which directly affect the service level and service satisfaction. 


\section{The model based on the weighting linear and optimal allocation of librarian's professional} ability

From analysis in the first part we can find that the differences between Chinese and American library are mainly embodied in three aspects. According to the nonlinear least squares theory, this is expressed as follows:

$$
R=g(x, b)=g(x, b 1, b 2, \ldots b m)
$$

Using curve fitting method, we can do curve fitting on $\mathrm{N}$ points, hypothesis that $\mathrm{N}$ fitting point

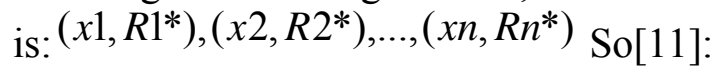

Solution of least squares meets[12]:

$$
R 1^{*}=\left\{\begin{array}{ll}
R 1^{*} \\
R 2^{*} \\
\vdots \\
R n^{*}
\end{array} \quad R 1=\left\{\begin{array}{cr}
R 1 & g(x 1: b) \\
R 2= & g(x 2 ; b) \\
\vdots & g(x 3 ; b) \\
R n & g(x 4 ; b)
\end{array}\right.\right.
$$

$$
X^{2}(b=\widetilde{b})=\left(R^{*}-R\right)^{T} \operatorname{Vr}\left(R^{*}-R\right) b=\widetilde{b}
$$

In which,

$$
\begin{gathered}
V r=C r^{-1} \cdot C r^{-1}=E\{[r-E(r)][y-E(y)]\} . \\
T=T_{e f} T_{e f}=\frac{\partial t\left(x_{e} ; b\right)}{\partial b_{f}}
\end{gathered}
$$

In this paper, we use professional statistical analysis software Minitab to get the optimized solution, and use the numerical successive iteration method to obtain the covariance matrix. The mathematics formula is[13]:

$$
C \tilde{b}=\left(T^{T} \operatorname{Vr} T\right)^{-1}
$$

The diagonal value of the covariance matrix can be used as a variance calculation, and ultimately get the estimating value of the direct data[14]:

$$
\widetilde{r}=r 0+g \tilde{b}
$$

\section{Optimal allocation of the librarian's skills based on the statistics software}

Through the optimization model in the second part, this paper use professional statistical analysis software Minitab to get the optimized solution. And Minitab can use numerical successive iteration method to obtain the covariance matrix, and then use the variance of diagonal value of the covariance matrix to do optimized calculation. Finally, through the optimization analysis, we get the optimal result of the settings of librarians, professional skills and service level. It's as shown in Figure 4 and Figure 5.
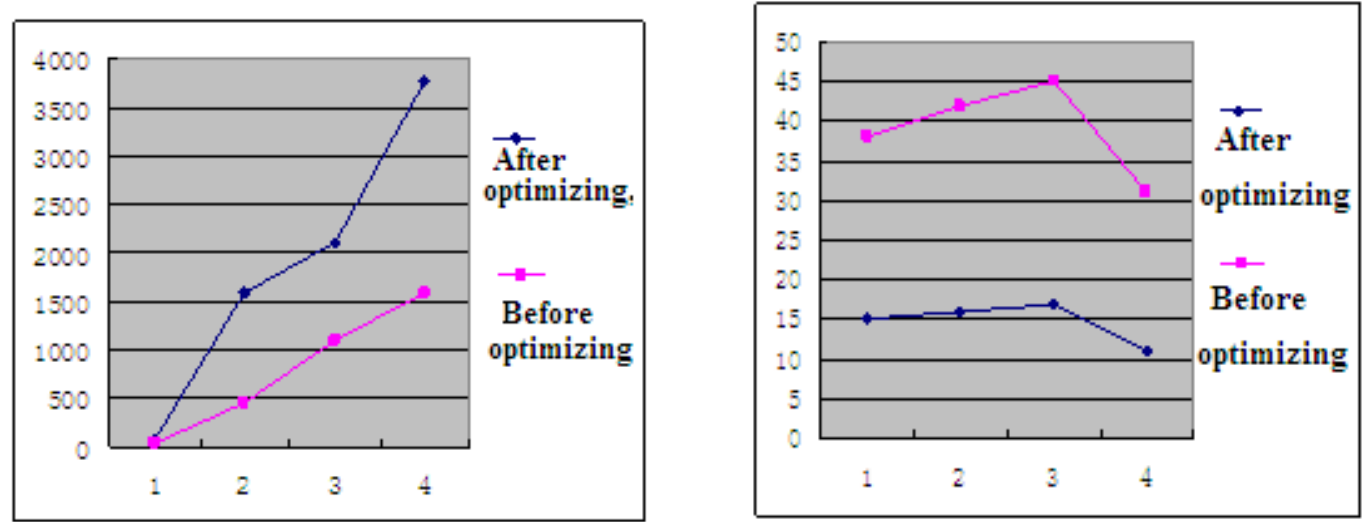
Through Figure 4 and Figure 5, we can see that if we want to improve the efficiency of management and quality of work, first of all, we are supposed to increase the number of librarians, and then through the constraints of candidates' education degree and retraining for librarians, we can conduct professional training on librarians. Finally, the service level of the librarians will be improved.

\section{Conclusion}

In this paper, the difference of Sino-American librarians has been studied in three aspects, namely, the settings of personnel, professional ability and service level. The first part of the paper exactly explains the difference in the three aspects. In the second part of the paper, by using the least square method, weighting linear and theoretical knowledge, the mathematical model was established for the the personnel settings of the librarians and the optimizing allocation of professional ability is established. In the third part, by foreign advanced statistical analysis software Minitab optimalizing and designing the data, the Figure of the settings of librarians and optimal allocation of professional ability is obtained. Through the Figure, we could preliminarily get the ideal data of the settings of librarians and allocation of professional ability. Thus it provided a theoretical basis for improving the speed and level of the library's management and service.

\section{Reference}

[1] Shali Zhang. Subject librarian of American University Library . Library and information work, 2008 (2) : 16-19.

[2] Mei Ye. Cooperative practice of librarians and subject teachers-the the experience and revelation of United States . Library BBS, 2007 (4) : 61-65

[3] Xiaofeng Yang. Online service survey and construction research of subject librarian in University Library. Library, 2009 (2) : 63-65.

[4] Dong Feng. The comparative study of the settings of China and American Subject Librarians. Library and information knowledge, 2008 (5) :59-60.

[5] Xudong Jin. The theory and practice of American University library's operating in the 21 st century. Beijing library press, 2007:88-89,104-105.

[6] Xiaoming Gu. The practice and discussion of subject librarian system. Library, 2007 (1):12-13.

[7] YangLin Li, XiaoPing Ji. Condition analysis on "211" key university subject librarians . Library, 2011 (1):56-59.

[8] Huizhen Li. The relevant practice discussion of university library establishing the subject librarian and system of subject information liaison staff . Books and information, 2012(5):3338

[9] Dequan Yao, Jie Zhao. The considerations and development of China copyright agency . Friends of the editor, 2012 (6) :19-22.

[10] Jiaru Luo. You Silu of copyright agency. Publishing wide-angle, 2010 (6) :42-44.

[11] Xianglian Deng. Growing with doing -- Private papers of copyright trade. Publishing science, $2012(27): 4-5$.

[12] Liping Wang. Analysis on the business of foreign publishers in China. Publishing science, 2012(1) : 23-26.

[13] Xuemin Zeng. Cultivation of copyright market and development of copyright agent. Publishing in China, 2013 (1) : 32-36.

[14] Jiangbo Xiang. What is the difference between the copyright agent of Chinese and western ? . Publishing reference, 2010(7) : 54-55. 